\title{
Implicações do agrupamento de inflorescências para a taxa de visitação por beija-flores e a produção de frutos de Heliconia bihai (L.) L. (Heliconiaceae)
}

\author{
Caio César Corrêa Missagia ${ }^{1 *}$ \\ Fábio de Castro Verçoza ${ }^{2}$

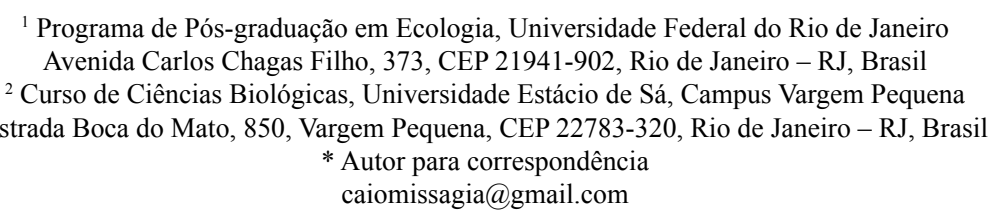

Submetido em 20/06/2014

Aceito para publicação em 25/03/2015

\section{Resumo}

A distribuição espacial de plantas pode influenciar a atividade de visitantes florais. $\mathrm{O}$ agrupamento de flores em manchas pode ser mais atrativo aos visitantes e supostamente influenciar a produção de frutos. Este estudo teve por objetivo testar a hipótese de que em Heliconia bihai (L.) L. (Heliconiaceae) o tamanho do agrupamento de inflorescências influencia positivamente a taxa de visitação e a produção de frutos da espécie. O estudo foi realizado em trecho de Mata Atlântica, no município do Rio de Janeiro. Foram registradas cinco espécies de beija-flores visitantes florais. A taxa de visitação média ( \pm desvio padrão) dos beija-flores foi de $2( \pm 0,56)$ visitas por hora por agrupamento. A quantidade de inflorescências por agrupamento influenciou positivamente a taxa de visitação dos beija-flores, mas influenciou negativamente a quantidade de frutos produzidos por inflorescência. De acordo com os resultados obtidos, sugerimos que a densidade de inflorescências em um agrupamento possa influenciar negativamente a quantidade de flores visitadas por cada inflorescência, em função de um aumento na quantidade de inflorescências incluídas nas rotas de forrageamento.

Palavras-chave: Polinização; Sucesso reprodutivo; Trochilidae

\section{Abstract}

Implications of inflorescence clustering for the visitation rate by hummingbirds and fruit production by Heliconia bihai (L.) L. (Heliconiaceae). Plant spatial distribution can influence the activity of floral visitors. Flower clustering in patches may be more attractive to visitors and it supposedly influences the fruit production. This study aimed to test the hypothesis that in Heliconia bihai (L.) L. (Heliconiaceae) the inflorescence clustering size positively influences the visitation rate and fruit production by the species. The study was conducted at a stretch of Atlantic Forest, in Rio de Janeiro city, Brazil. Five hummingbird species were registered as floral visitors. The average visitation rate ( \pm standard deviation) of hummingbirds was $2( \pm 0.56)$ visits per hour per clustering. The amount of inflorescences per clustering positively influenced the visitation rate of hummingbirds, but it negatively influenced the amount of fruits produced per inflorescence. According to the results obtained, we suggest that the density of inflorescences in a clustering may negatively influence the number of flowers visited per inflorescence, due to an increased amount of inflorescences included in the foraging routes.

Key words: Pollination; Reproductive success; Trochilidae 


\section{Introdução}

Plantas polinizadas por animais apresentam diferentes estratégias de atração de visitantes florais, tais como a morfologia floral (GOULSON et al., 2007), a densidade e agrupamento de flores e inflorescências (HIXON, 1980; KUNIN, 1993), ou a composição química do néctar floral (WRIGHT et al., 2013), dentre outras. Em espécies de plantas ornitófilas, a distribuição espacial em manchas forma agrupamentos de flores que podem ter implicações na taxa de visitação das aves, quando potencializa a atração de visitantes florais (FEINSINGER et al., 1991; CORBET, 1998). O aumento na taxa de visitação pode estar relacionado positivamente com o aumento no sucesso reprodutivo da planta, quando ocasiona um maior fluxo de pólen entre as flores visitadas (SIQUEIRA FILHO; MACHADO, 2001).

Heliconia bihai (L.) L. (Heliconiaceae) é uma espécie herbácea autocompatível (MELENDEZACKERMAN et al., 2008) com ampla distribuição pela Região Neotropical (KRESS, 1990). Suas flores são potencialmente polinizadas por beija-flores (MISSAGIA; VERÇOZA, 2011) e seus indivíduos podem formar agrupamentos adensados apresentando diversas inflorescências (CASTRO et al., 2011). Nós testamos a hipótese de que a quantidade de inflorescências disponíveis em agrupamentos dessa espécie tenha influência na taxa de visitação por beija-flores e na quantidade de frutos formados por inflorescência em trecho de Mata Atlântica, no município do Rio de Janeiro.

\section{Material e Métodos}

O estudo foi desenvolvido entre os meses de dezembro de 2012 e abril de 2013, em trecho de mata próximo aos limites do Parque Estadual da Pedra Branca, em uma propriedade particular no bairro Vargem Grande, Rio de Janeiro. A vegetação do local corresponde a Floresta Ombrófila Densa (IBGE, 1992) e as coordenadas geográficas do local são $22^{\circ} 57^{\prime}$ S, $43^{\circ} 29^{\prime} \mathrm{W}$. Em uma transecção com aproximadamente $800 \mathrm{~m}$ foram considerados 23 agrupamentos (manchas) de $H$. bihai com inflorescências em formação. A identificação da planta foi feita utilizando literatura especializada (BERRY; KRESS, 1991; CASTRO et al., 2011). Em cada agrupamento foi considerada a quantidade de inflorescências e de frutos formados por inflorescência. A contagem de frutos de cada inflorescência ocorreu 60 dias após o início da floração.

Para cada agrupamento houve quatro períodos de observações focais com duração de $3 \mathrm{~h}$ em diferentes dias, iniciando às 06h00min até as $18 \mathrm{~h} 00 \mathrm{~min}$ para determinar as espécies e a taxa de visitação $(\mathrm{T}=$ número de visitas legítimas por hora por agrupamento) de visitantes florais de $H$. bihai. Os animais foram identificados com o auxilio de guia de identificação (PERLO, 2009). Cada aproximação do animal ao agrupamento, seguida por visita floral legítima (INOUYE, 1980), foi considerada como uma visita floral, independentemente de quantas flores ou inflorescências receberam visitas. Foi testada a influência da quantidade de inflorescências por agrupamento na taxa de visitação de potenciais polinizadores (para a soma total e também para cada uma das espécies observadas), bem como na quantidade de frutos produzidos por inflorescência, utilizando regressão linear $\left(\mathrm{r}^{2}, \mathrm{p}<0,05\right)$. A mesma análise foi utilizada entre taxa de visitação e número de frutos formados por inflorescência.

\section{Resultados}

Os agrupamentos de $H$. bihai monitorados apresentaram entre cinco e 17 inflorescências cada (Tabela 1). As flores apresentaram coloração brancoamarelada, corolas tubulosas, ausência de odores e duração de um dia. Seus frutos se formaram com aproximadamente 30 dias, adquirindo coloração azulada em cerca de 60 dias. Os visitantes florais registrados e respectivas taxas de visitação $(\mathrm{T}=$ taxa \pm desvio padrão) foram os beija-flores Trochilinae Eupetomena macroura (Gmelin, 1788) $(\mathrm{T}=0,89 \pm 0,48)$, Thalurania glaucopis (Gmelin, 1788) $(\mathrm{T}=0,65 \pm 0,29)$ e Amazilia fimbriata Vigors, $1825(\mathrm{~T}=0,03 \pm 0,07)$. E os Phaethornithinae Ramphodon naevius (Dumont, 1818) $(\mathrm{T}=0,27 \pm 0,22)$ e Phaethornis ruber (Linnaeus, 1758) $(\mathrm{T}=0,15 \pm 0,14)$. A taxa de visitação média de beija-flores (todas as espécies) foi de $2( \pm 0,56)$ visitas por hora, sendo maior 
TABELA 1: Quantidade de inflorescências, de frutos, e taxa de visitação ( $T=$ visitas/hora) por beija-flores por mancha monitorada de Heliconia bihai (Heliconiaceae) em trecho de Mata Atlântica no Rio de Janeiro, RJ.

\begin{tabular}{lcccc}
\hline & Inflorescências & Frutos & Média (frutos/inflorescência) & Taxa de visitação \\
\hline Mancha 1 & 10 & 1344 & 134 & 2,1 \\
Mancha 2 & 15 & 1189 & 79 & 2,3 \\
Mancha 3 & 12 & 817 & 68 & 1,8 \\
Mancha 4 & 7 & 595 & 85 & 2,3 \\
Mancha 5 & 6 & 663 & 110 & 1,9 \\
Mancha 6 & 16 & 1546 & 96 & 3,1 \\
Mancha 7 & 7 & 891 & 127 & 1,0 \\
Mancha 8 & 11 & 962 & 87 & 1,8 \\
Mancha 9 & 13 & 1388 & 106 & 1,6 \\
Mancha 10 & 13 & 1073 & 82 & 2,1 \\
Mancha 11 & 8 & 1077 & 134 & 1,7 \\
Mancha 12 & 17 & 1039 & 61 & 2,7 \\
Mancha 13 & 8 & 983 & 122 & 1,3 \\
Mancha 14 & 14 & 1056 & 75 & 1,7 \\
Mancha 15 & 15 & 1225 & 81 & 2,6 \\
Mancha 16 & 16 & 1431 & 89 & 3,0 \\
Mancha 17 & 9 & 489 & 54 & 1,6 \\
Mancha 18 & 11 & 1153 & 104 & 2,3 \\
Mancha 19 & 14 & 1471 & 705 & 2,8 \\
Mancha 20 & 10 & 755 & 87 & 1,8 \\
Mancha 21 & 7 & 611 & 112 & 1,8 \\
Mancha 22 & 5 & 564 & 98 & 1,3 \\
Mancha 23 & 9 & 889 & & 1,4 \\
\hline
\end{tabular}

a frequência pela manhã $(T=1,1 \pm 0,78)$, em relação à tarde $(\mathrm{T}=0,8 \pm 0,69)$. A quantidade de inflorescências por agrupamento influenciou positivamente a taxa de visitação dos beija-flores $\left(r^{2}=0,52 ; p<0,00009\right)$ (Figura 1a), e também influenciou negativamente a quantidade de frutos produzidos por inflorescência $\left(\mathrm{r}^{2}=0,20\right.$; $\mathrm{p}=0,03$ ) (Figura 1b). Quando calculado para cada espécie de beija-flor, apenas as visitas florais de E. macroura foram relacionadas à quantidade de inflorescências do agrupamento $\left(\mathrm{r}^{2}=0,34, \mathrm{p}=0,003\right)$ (Figura 1c). Não houve relação significativa entre taxa de visitação e quantidade de frutos por inflorescência $\left(r^{2}=0,08\right.$; $\mathrm{p}=0,18)$.

\section{Discussão}

A relação entre agrupamento de flores e a produção de frutos por inflorescência de $H$. bihai diferiu de resultados apresentados em estudo com Heliconia na
Amazônia brasileira (BRUNA et al., 2004). Os autores observaram não haver relação entre as variáveis, e citam uma taxa de visitação (total de visitas por horas observadas) inferior $(\mathrm{T}=0,22)$ se comparada à observada no presente estudo $(T=2)$. A taxa de visitação pode influenciar a produção de frutos em uma população (SIQUEIRA FILHO; MACHADO, 2001; LONGO; FISCHER, 2006). Contudo, a ausência de relação entre taxa de visitação por beija-flores e produção de frutos observada no presente estudo indica que esta não foi uma variável à qual a produção de frutos de $H$. bihai tenha sido dependente.

A influência do agrupamento de inflorescências sobre a taxa de visitação dos beija-flores observado no presente trabalho corrobora com experimentos de campo desenvolvidos na Costa Rica (FEINSINGER et al., 1991) e com um trabalho realizado na mesma área de estudo do presente trabalho, no qual apenas o beijaflor E. macroura apresentou maiores taxas de visitação e 
FIGURA 1: Relação entre variáveis dependentes (a,b,c) e a quantidade de inflorescências em agrupamentos de Heliconia bihai (Heliconiaceae). a) Taxa de visitação $\left(T=\right.$ visitas/hora) dos potenciais polinizadores $\left(r^{2}=0,52, p=0,00009\right)$. b) Produção de frutos/inflorescência (média) $\left(\mathrm{r}^{2}=0,2, \mathrm{p}=0,03\right)$. c) Visitas florais do beija-flor Eupetomena macroura $($ Trochilidae $)\left(\mathrm{r}^{2}=0,34\right.$, $\mathrm{p}=0,003)$.

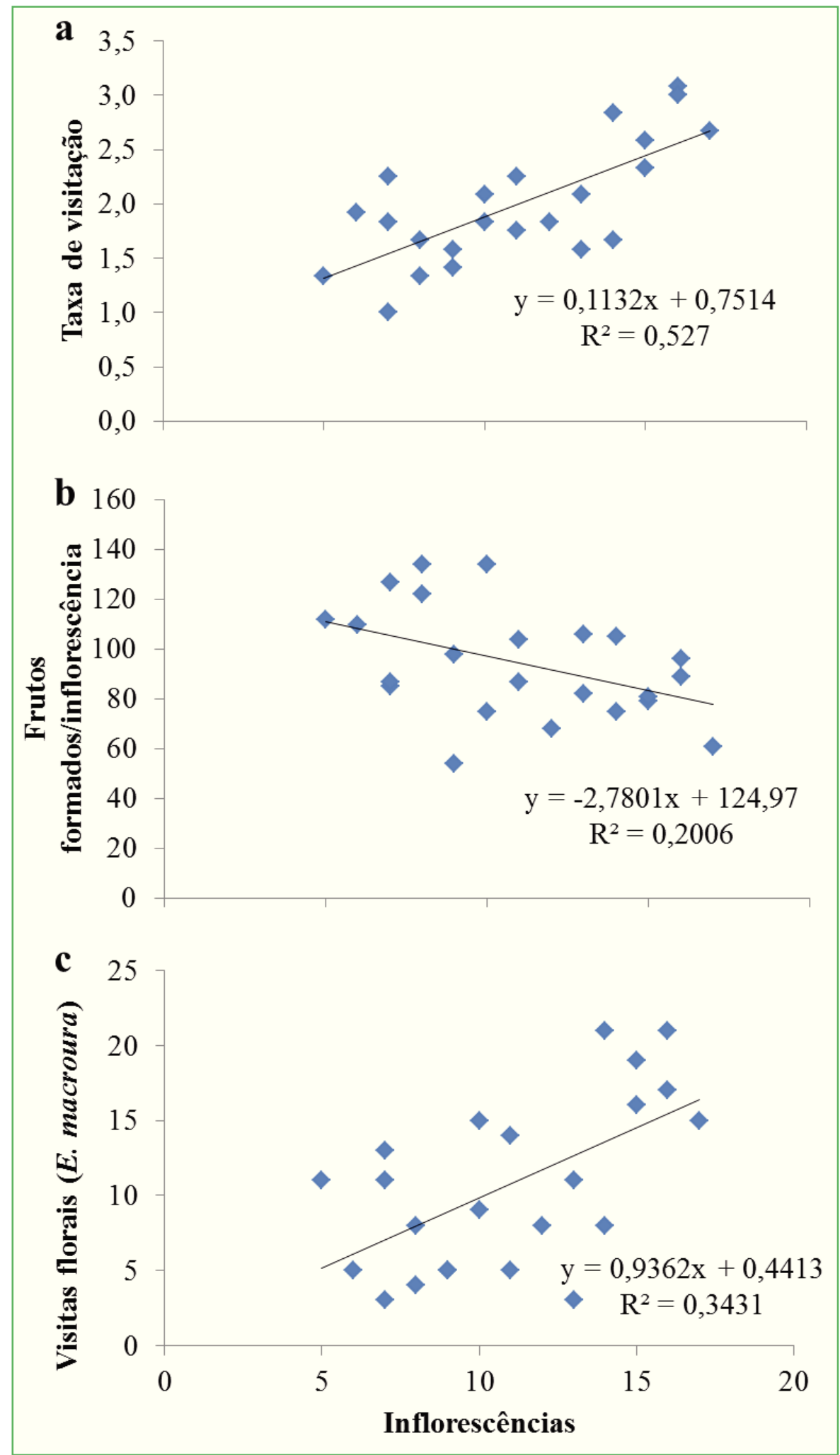


comportamento agonístico em agrupamentos com maior número de inflorescências de Odontonema strictum (Nees) Kuntze (Acanthaceae) (MISSAGIA; VERÇOZA, 2014). Entretanto, a relação negativa entre tamanho do agrupamento e produção de frutos foi contrária ao esperado (FEINSINGER et al., 1991). Conjecturamos que agrupamentos maiores puderam ter um efeito negativo na produção de frutos por inflorescência por diminuir a quantidade de visitas em cada inflorescência, à custa de um aumento na quantidade de inflorescências visitadas. Essa é uma hipótese que deve ser testada, embora outros fatores também possam influenciar a produção de frutos de uma espécie, como florações de espécies simpátricas ou alocação de recurso (STEPHENSON, 1981; FEINSINGER et al., 1991).

Quando há partilha de polinizadores entre espécies simpátricas com florações sobrepostas, os efeitos da variação na densidade de inflorescências de uma espécie (e supostamente sua atratividade a polinizadores) podem ser inviabilizados. Nesse caso a partilha de polinizadores entre plantas simpátricas pode diminuir a intensidade da atração que agrupamentos exercem sobre os beija-flores em função da atração exercida por coespecíficos, ou por outras espécies (FEINSINGER et al., 1991; BRUNA et al., 2004). Outro fator de influência pode ser a alocação de recurso entre as funções fisiológicas da planta, já que mesmo havendo fecundação o fruto em desenvolvimento pode ser abortado em função da disponibilidade limitada de recurso a ser alocado para a reprodução durante um evento reprodutivo (STEPHENSON, 1981).

Embora aparentemente esteja reduzindo o valor adaptativo de indivíduos de $H$. bihai, a relação negativa entre agrupamento de inflorescências e produção de frutos pode ser vantajosa para a espécie de planta caso seja acompanhada de um aumento na quantidade de indivíduos visitados pelos polinizadores, e consequentemente, promova um aumento do fluxo gênico (JORDANO, 2010). Heliconia bihai é uma espécie autocompatível que não realiza autopolinização espontânea (MELENDEZ-ACKERMAN et al., 2008) e que apresenta até três sementes por fruto (SANTOS, 1978). Assim, é possível que haja uma variação em termos de quantidade ou qualidade de sementes associada ao fluxo intraespecífico de pólen desta espécie.
Os resultados apresentados no presente estudo indicam que na população estudada a taxa de visitação por potenciais polinizadores, assim como a produção de frutos de $H$. bihai, foram influenciadas pelo tamanho do agrupamento de inflorescências. Estudos futuros poderão testar a hipótese de haver uma relação negativa entre a quantidade de inflorescências visitadas por beijaflores em agrupamentos e a produção de frutos por inflorescência do agrupamento, conforme foi especulado no presente trabalho.

\section{Referências}

BERRY, F.; KRESS, W. J. Heliconia: an identification guide. 1. ed. Washington: Smithsonian Institution Press, 1991. 334 p.

BRUNA, E. M.; KRESS, W. J.; MARQUES, F.; SILVA, O. F. Heliconia acuminata reproductive success is independent of local floral density. Acta Amazonica, Manaus, n. 34, v. 3, p. 467-471, 2004.

CASTRO, C. D. F.; GONÇALVES, C.; MOREIRA, S. R.; FARIA, O. A. Helicônias brasileiras: características, ocorrência e usos. Revista Brasileira de Horticultura Ornamental, Campinas, v. 17, n. 1, p. 5-24, 2011.

CORBET, S. A. Fruit and seed production in relation to pollination and resources in bluebell, Hyacinthoides nonscripta. Oecologia, Heidelberg, n. 114, p. 349-360, 1998.

FEINSINGER, P.; TIEBOUT, H. M.; YOUNG, B. E. Do tropical bird-pollinated plants exhibit density-dependent interactions? Field experiments. Ecology, New York, n. 72, p. 1953-1963, 1991.

GOULSON, D.; CRUISE, J. L.; SPARROW, K. R.; HARRIS, A. J.; PARK, K. J.; TINSLEY, M. C.; GILBURN, A. S. Choosing rewarding flowers; perceptual limitations and innate preferences influence and honeybees. Behavioral Ecology and Sociobiology, Göttingen, n. 61, p. 1523-1529, 2007.

HIXON, M. A. Food production and competitor density as the determinants of feeding territory size. The American Naturalist, Chicago, v. 5, n. 11, p. 510-530, 1980.

IBGE. Manual técnico da vegetação brasileira. N. 1. Série Manuais Técnicos em Geociências. Rio de Janeiro: IBGE, 1992. 89 p.

INOUYE, D.W. The terminology of floral larceny. Ecology, New York, n. 61, p. 1251-1253, 1980.

JORDANO, P. Pollen, seeds and genes: the movement ecology of plants. Heredity, Sheffield, n. 105, p. 229-230, 2010.

KRESS, J. The diversity and distribution of Heliconia (Heliconiaceae) in Brazil. Acta Botanica Brasilica, Feira de Santana, v. 1, n. 4, p. 159-167, 1990.

KUNIN, W. E. Sex and the single mustard: population density and pollinator behavior effects on seed set. Ecology, New York, n. 74, p. 2145-2160, 1993.

LONGO, J. M.; FISCHER. E. Efeito da taxa de secreção de néctar sobre a polinização e a produção de sementes em flores de 
Passiflora speciosa Gardn. (Passifloraceae) no Pantanal. Revista Brasileira de Botânica, São Paulo, v. 29, v. 3, p. 481-488, 2006.

MISSAGIA, C. C. C.; VERÇOZA, F. C. Fenologia reprodutiva, polinização e frutificação de Heliconia spathocircinata Aristeg. (Heliconiaceae) em trecho de Floresta Atlântica no município do Rio de Janeiro. Biotemas, Florianópolis, v. 24, n. 3, p. 13-23, 2011.

MISSAGIA, C.C.C.; VERÇOZA, F. C. Influência da disponibilidade de recurso floral no comportamento de forrageamento de Eupetomena macroura (Trochilidae). Atualidades Ornitológicas, Ivaiporã, v. 180, p. 4-6, 2014.

MELENDÉZ, E.; ROJAS-SANDOVAL, J.; PLANAS, S. Self-compatibility of microgametophytes in Heliconia bihai (Heliconiaceae) from St. Lucia. Caribbean Journal of Science, Mayagüez, v. 2, n. 44, p. 145-149, 2008.
SANTOS, E. Revisão das espécies do gênero Heliconia L. (Musaceae s.1.) espontâneas na região fluminense. Rodriguésia, Rio de Janeiro, n. 30, p. 99-201, 1978.

SIQUEIRA-FILHO, J. A.; MACHADO, I. C. S. Biologia reprodutiva de Canistrum aurantiacum E. Morren (Bromeliaceae) em remanescente da floresta atlântica, nordeste do Brasil. Acta Botanica Brasilica, Feira de Santana, v. 2, n. 15, p. 427-443, 2001. STEPHENSON, A. G. Flower and fruit abortion: proximate causes and ultimate functions. Annual Review of Ecology and Systematics, Palo Alto, v. 12, p. 253-279, 1981.

WRIGHT, G. A.; BAKER, D. D.; PALMER, M. J.; STABLER, D.; MUSTARD, J. A.; POWER, E. F.; BORLAND, A. M.; STEVENSON P. C. Caffeine in floral nectar enhances a pollinator's memory of reward. Science, New York, v. 6124, n. 339, p. $1202-$ 1204, 2013. 